05

\title{
Следы фазовых превращений меди при высокоскоростном внедрении в металлы
}

\author{
(С) А.И. Козачук ${ }^{1}$, А.И. Михайлин ${ }^{2}$, С.И. Павлов ${ }^{1}$, Б.В. Румянцев ${ }^{1, \uparrow, ~ М . В . ~ С и л ь н и к о в ~}{ }^{2}$ \\ ${ }^{1}$ Физико-технический институт им. А.Ф. Иофрфе РАН, Санкт-Петербург, Россия \\ 2 ЗАО „Научно-производственное объединение специальных материалов“, \\ Санкт-Петербург, Россия \\ ๑E-mail: brum@mail.ioffe.ru
}

Поступило в Редакцию 1 ноября 2018г.

В окончательной редакции 4 декабря 2018г.

Принято к публикации 4 декабря 2018г.

Регистрируется и анализируется состояние поверхности каверны после внедрения медной струи в металлическую преграду. Осуществлено сравнение поверхности каверны для струй, обеспечивающих только плавление или плавление с испарением при разгрузке ударно-сжатой меди. Зафиксированы конечные стадии развития пор при затвердевании. Проведена оценка объемной доли испарения. Быстрая разгрузка области внедрения, зарождение пор в объеме до разрушения в слое растекания струи объясняют увеличение эффективности экранной защиты космических аппаратов при испарении фрагмента техногенного мусора.

DOI: 10.21883/PJTF.2019.05.47389.17578

Фазовые превращения металлов (плавление, испарение) широко изучены при изменении температуры без значительного изменения давления. При больших давлениях, превышающих прочностные характеристики, твердая структура нарушается и металлы плавятся. При дальнейшем увеличении давления металл переходит в плазменное состояние. Такой уровень давлений достигается в специальных устройствах (прессах), массивных телах (планетах), ударных волнах при высоких скоростях взаимодействия твердых тел. Для исследований такие состояния создаются в ограниченной области и на короткие времена, после чего неизбежно происходит расширение области повышенного давления с возможным испарением, конденсацией и затвердеванием. Поведение металлов в этих процессах, а также связь параметров (давления, температуры) описываются современными моделями, в частности широкодиапазонным уравнением состояния [1].

Одним из способов создания сверхвысоких давлений в конденсированных средах является внедрение высокоскоростной металлической струи, полученной при схлопывании металлического конуса под действием продуктов детонации взрывчатого вещества. Применение промышленных взрывчатых веществ позволяет получать струи из металла массой до $1 \mathrm{~g}$ со скоростью до $12 \mathrm{~km} / \mathrm{s}$ [2]. В работе рассматриваются медные струи, практическое применение которых наиболее широко распространено.

В работе [3] предложено использовать такие струи при исследовании экранной защиты космического аппарата от техногенного мусора в околоземном пространстве. В отличие от компактного ударника струя моделирует действие удлиненного фрагмента техногенного мусора, который наиболее опасен при совпадении направления движения с осью фрагмента и нормалью к по- верхности стенки космического аппарата. Полученные экспериментальные результаты [4,5] свидетельствуют о дестабилизации значительных участков медной струи со скоростью $8-7 \mathrm{~km} / \mathrm{s}$ после прохождения металлической экранной защиты и влиянии на этот процесс фазового состояния взаимодействующих материалов.

В настоящей работе исследовалась поверхность остаточной каверны с целью идентификации следов фазовых превращений медной струи после высокоскоростного внедрения в металлы.

Высокоскоростные струи получались при обжатии медного тонкостенного конуса 2 продуктами детонации заряда взрывчатого вещества в устройстве 1 (рис. 1). Струя внедрялась в металлическую преграду 3 с углублением.

Эксперимент проводился при соблюдении следующих условий:

- модельный вариант сочетания медного ударника и медной преграды, обеспечивающий равенство скоростей внедрения и образования поверхности каверны;

- „мгновенная“ герметизация полости каверны для исключения заноса продуктов детонации от устройства 1 получения струи, остаточное давление воздуха менее $10^{4} \mathrm{~Pa}$.

В таблице приведены параметры струй [3] для устройств 1 (рис. 1) с массой взрывчатого вещества $40 \mathrm{~g}$ и медным конусом 2 толщиной $0.8 \mathrm{~mm}$ с полным углом при вершине 30 и $60^{\circ}$. Углубление в медной преграде 3 составляло $10 \mathrm{~mm}$. Там же приведены давления соударения [6], плавления и начальное давление на ударной адиабате (УА), обеспечивающее при разгрузке испарение меди [1]. Сопоставление давлений показывает, что струи от устройств обеспечивают плавление ударника в зоне внедрения и испарение только в случае медного конуса с углом при вершине $30^{\circ}$. Полученная преграда 
Параметры струй, давления внедрения и фазовых превращений

\begin{tabular}{|c|c|c|c|c|c|c|c|}
\hline \multirow[b]{2}{*}{$\begin{array}{c}\text { Угол } \\
\text { конуса, }\end{array}$} & \multirow[b]{2}{*}{$\begin{array}{c}\text { Скорость, } \\
\mathrm{km} / \mathrm{s}\end{array}$} & \multirow[b]{2}{*}{$\begin{array}{c}\text { Энергия, } \\
\text { kJ }\end{array}$} & \multirow[b]{2}{*}{$\begin{array}{l}\text { Macca, } \\
10^{-3} \mathrm{~kg}\end{array}$} & \multirow[b]{2}{*}{$\begin{array}{c}\text { Диаметр, } \\
\text { mm }\end{array}$} & \multicolumn{3}{|c|}{ Давление, GPa } \\
\hline & & & & & $\begin{array}{c}\text { внедрения } \\
\text { в медь }\end{array}$ & $\begin{array}{c}\text { плавления } \\
\text { на УА }\end{array}$ & $\begin{array}{c}\text { на УА для } \\
\text { испарения при } \\
\text { разгрузке }\end{array}$ \\
\hline $\begin{array}{l}30 \\
60\end{array}$ & $\begin{array}{l}8.0 \\
6.2\end{array}$ & $\begin{array}{r}11.0 \\
7.6\end{array}$ & $\begin{array}{l}0.34 \\
0.40\end{array}$ & $\begin{array}{l}0.82 \\
1.30\end{array}$ & $\begin{array}{l}350 \\
240\end{array}$ & $\begin{array}{c}190-270 \\
{[1]}\end{array}$ & $\begin{array}{c}270 \\
{[1]}\end{array}$ \\
\hline
\end{tabular}

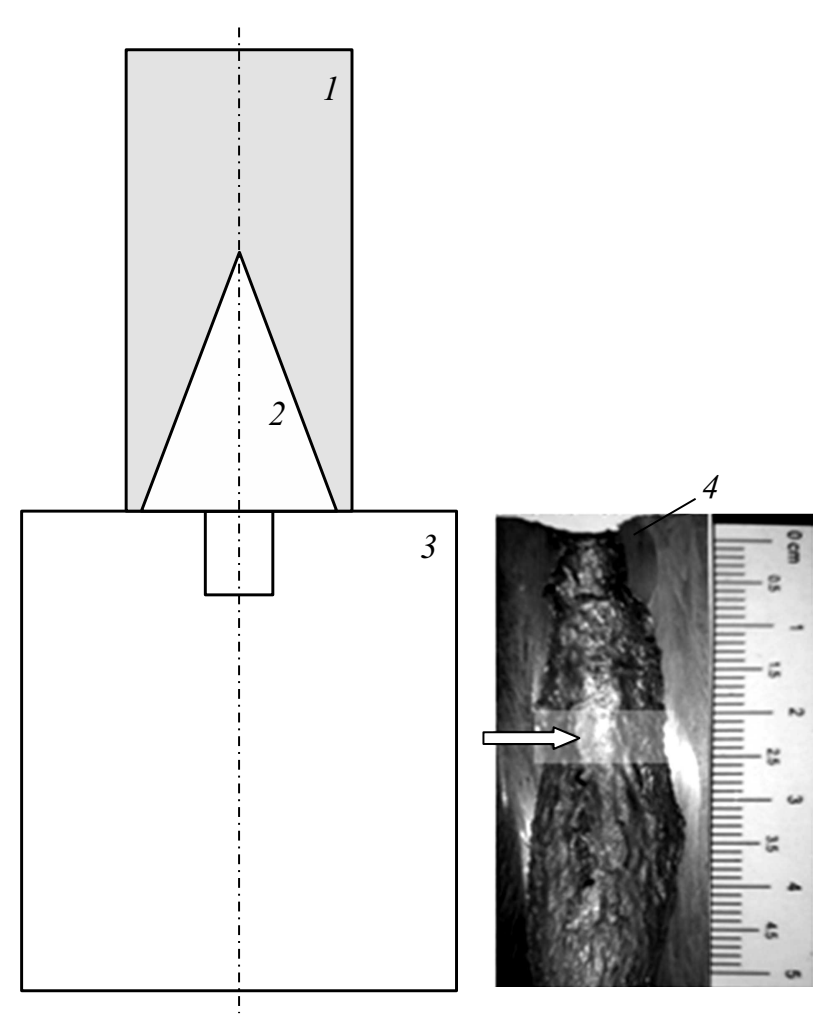

Рис. 1. Схема эксперимента по получению и поглощению струи. Стрелкой обозначена область исследования полученной каверны. Пояснения приведены в тексте.

с каверной 4 разрезалась по оси и выделялся сектор с областью (рис. 1) для исследований на растровом электронном микроскопе (РЭМ) JSM 7001F (JEOL) в Федеральном ЦКП „Материаловедение и диагностика в передовых технологиях“ при ФТИ им. А.Ф. Иоффе.

Гидродинамические представления о растекании жидкой струи по стенкам каверны могут меняться при увеличении скорости внедрения до значений, при которых ударно-сжатые материалы в зоне внедрения при разгрузке будут частично испаряться. На предсказуемое разграничение могут повлиять начальная температура струи 800-900 $\mathrm{C}$ [7] и относительная малость области повышенного давления.

На рис. 2, $a$ и $c$ приведены РЭМ-изображения поверхности каверны в меди. Видно, что поверхности каверн при разных скоростях качественно различаются.
В случае внедрения струи со скоростью $6.2 \mathrm{~km} / \mathrm{s}$ медь распределилась в виде однородного массива частиц и агломератов размером $1-3 \mu \mathrm{m}$, разделенного трещинами, отражающими хрупкий характер покрытия (рис. 2,a) [8]. На рис. 2, $c$ приведена поверхность каверны, образованная при внедрении медной струи со скоростью $8.0 \mathrm{~km} / \mathrm{s}$. Изображение отражает „замороженную“ картину кипящей вязкой жидкости. Хорошо видны затвердевшие подтеки меди, которые заканчиваются сферическими образованиями. Промежутки между ними заполнены разнообразными по форме фрагментами.

Качественный характер покрытий соответствует фазовому состоянию меди при разгрузке зоны внедрения с попаданием в двухфазную область жидкость-пар [1]. Таким образом, приведенные изображения (рис. 2, $a$ и $c$ ) показывают, что медная струя при внедрении со скоростью $6.2 \mathrm{~km} / \mathrm{s}$ плавится и при растекании по каверне быстро твердеет с измельчением до агломератов. Струя со скоростью $8.0 \mathrm{~km} / \mathrm{s}$ в зоне внедрения также находится в жидком состоянии, но при разгрузке частично испаряется и вскипает как перегретая жидкость. На рис. 2, $b$ приведена схема растекания струи при внедрении в преграду. Левая часть схемы отражает гидродинамическое растекание жидкой струи в пелену толщиной $\sim 10 \mu \mathrm{m} \mathrm{c}$ затвердеванием. На правой части схемы отображено растекание струи с эволюцией газовой поры при расширении каверны. С приходом волны разгрузки поры растут и могут выходить за пределы жидкой пленки, при этом формируются сферические образования (пузыри) (рис. 2,c). Волнообразная поверхность сферических образований отражает пульсации давления в поре. Разгрузка, охлаждение и рост вязкости „замораживают“ расширение пор. Максимальное время эволюции пор ограничивается разгрузкой зоны внедрения и составляет доли микросекунды. Бо́льшая часть „пузырьков“ при выходе на свободную поверхность разрушается (рис. 3,a), а затвердевшие фрагменты оболочки пор толщиной $1-2 \mu \mathrm{m}$ (показаны стрелками на рис. 2,c) занимают основную площадь покрытия поверхности каверны. При разрушении открываются агломераты размером 2-10 $\mu \mathrm{m}$, образованные при конденсации испаренной фазы (рис. 3,b). Аналогичные агломераты наблюдаются при вскрытии электроосажденных частиц меди [9].

Исходя из распределения по размерам $(D, \mu \mathrm{m})$ coхранившихся сферических образований $n=1.3 \cdot 10^{3} D^{-1.5}$ и 


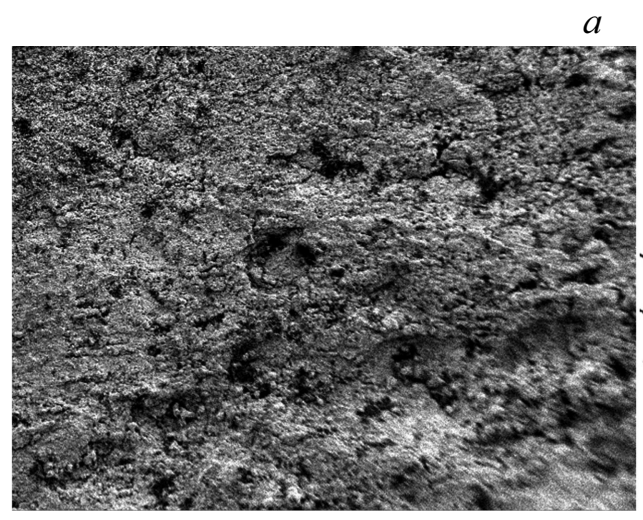

$-100 \mu \mathrm{m}$ $b$

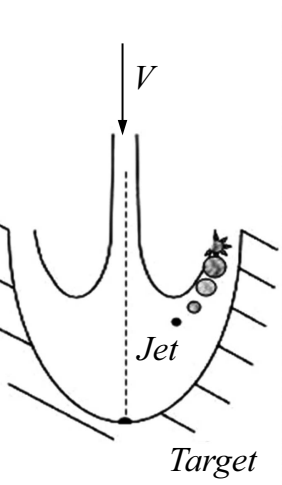

Target

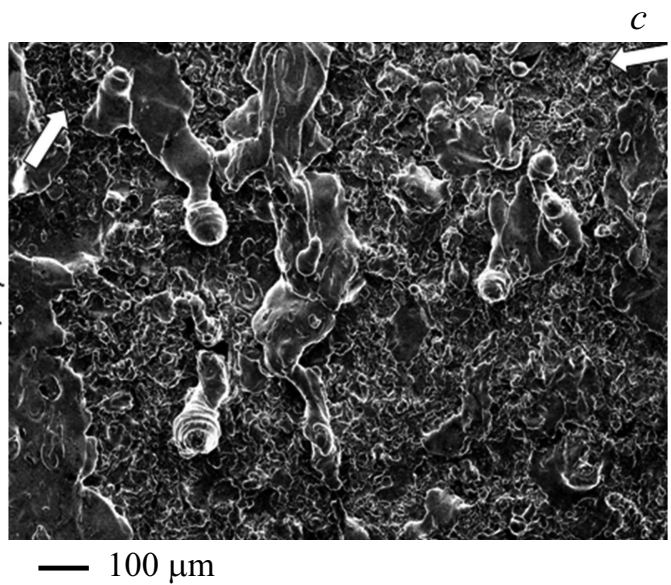

Рис. 2. РЭМ-изображения поверхности каверн, образованных при внедрении медной струи со скоростью 6.2 (a) и $8.0 \mathrm{~km} / \mathrm{s}(\mathrm{c})$; $b-$ схема внедрения и эволюции поры при расширении каверны.
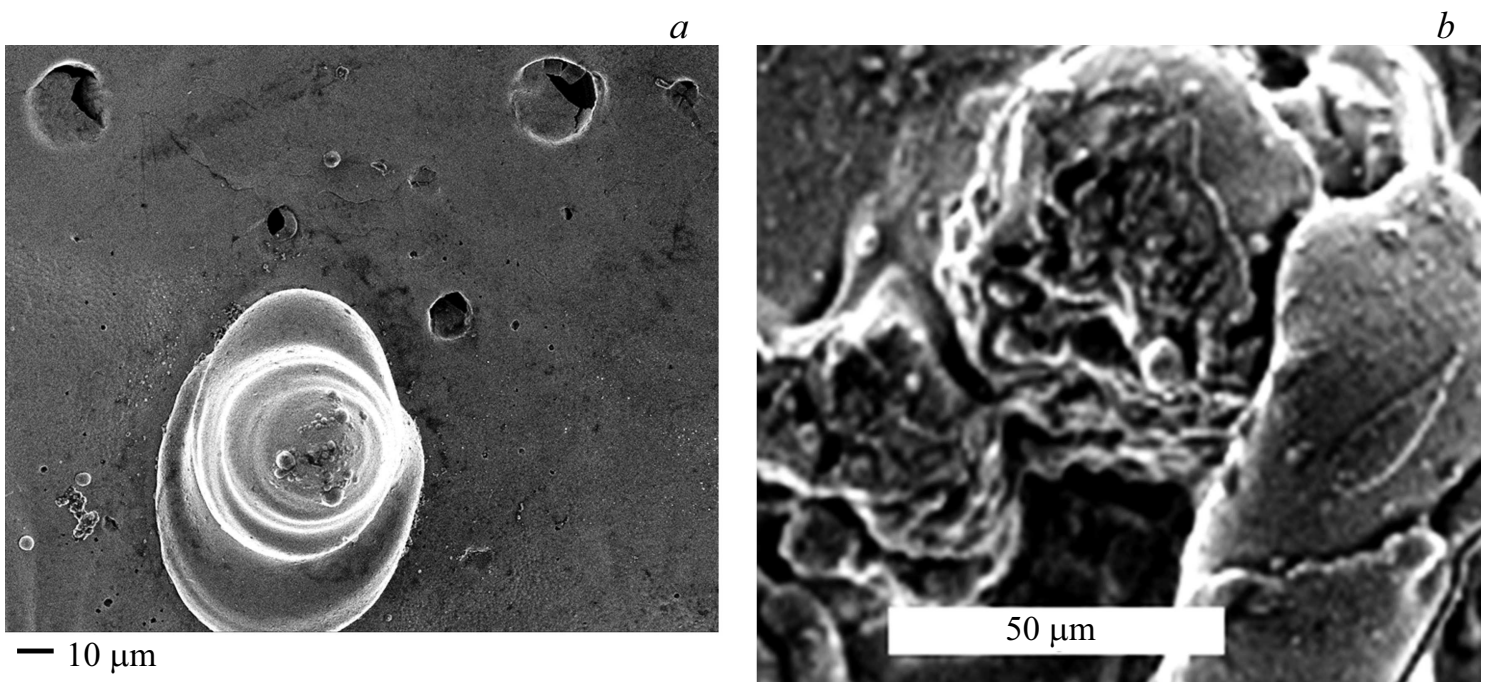

Рис. 3. $a-$ локальное разрушение поверхности оболочки поры; $b-$ поверхность разрушенного сферического образования.

при допущении постоянства его по всей области наблюдения проведена оценка испарившейся доли объема ударника, которая составила 11\%.

Анализ остаточной каверны после кипения и разрушения твердеющей пористой жидкой меди позволяет предположить, что частицы меди могут попадать на последующие части струи, инициировать их разрушение и диспергирование. Эффективность этого процесса зависит от количества паров, характера разрушения, движения фрагментов оболочки пор. Прямая оценка массы и импульса частиц, движущихся в направлении к струе, представляет в настоящее время проблему. С другой стороны, в работе [5] на основе анализа кинетики внедрения аналогичной струи в экранированную преграду были определены время обратной реакции и размер возмущенной части струи после прохождения тонкого медного экрана. Таким образом, высказанное вы- ше предположение позволяет объяснить процесс дестабилизации высокоскоростной струи на экранной защите.

На основании полученных результатов можно сделать следующие выводы:

- испарение струи (ударника) при достижении соответствующих давлений на УА (300 GPa для меди) существенно изменяет гидродинамический характер разгрузки области высокоскоростного взаимодействия;

- распределение частично испарившейся струи по поверхности каверны представляет собой „замороженную“ картину кипящей вязкой жидкости;

- для исходного давления ударно-сжатой меди $350 \mathrm{GPa}$ объемная доля пара составляет $11 \%$;

- анализ следов фазовых превращений меди при скорости внедрения более $7 \mathrm{~km} / \mathrm{s}$ позволяет объяснить дестабилизацию медной струи при прохождении тонких металлических экранов $[4,5]$. 
Исследование выполнено при финансовой поддержке РФФИ в рамках научного проекта № 18-08-00487/18.

\section{Список литературы}

[1] Каннель Г.И., Разоренов С.В., Уткин А.В., Фортов В.Е. Ударно-волновые явления в конденсированных средах. М.: Янус, 1996. 408 c.

[2] Christiansen E.L. Meteoroid/debris shielding. TP-2003210788. Houston, Texas: NASA Johnson Space Center, 2003. P. 41.

[3] Rumyantsev B.V., Mikhaylin A.I. // Acta Astron. 2015. V. 109. P. 166-171. http://www.sciencedirect.com/science/article/pii/ S0094576514004949

[4] Rumiantsev B.V., Mikhaylin A.I. // Acta Astron. 2017. V. 135. P. 15-20. http://www.sciencedirect.com/science/article/pii/ S0094576516309183

[5] Румянщев Б.В., Михайлин А.И. // Письма в ЖТФ. 2018. T. 44. B. 3. C. $62-68$.

DOI: 10.21883/PJTF.2018.03.45580.16970

[6] http://www.ihed.ras.ru/rusbank/ [Электронный pecypc].

[7] Физика взрыва / Под ред. Л.П. Орленко. Изд. 3-е, перераб. М.: ФИЗМАТЛИТ, 2002. Т. 2. $656 \mathrm{c.}$

[8] http://www.microstructure.ru [Электронный pecypc].

[9] Викарчук А.А., Дорогов М.В. // Письма в ЖЭТФ. 2013. Т. 97. B. 10. C. $682-686$. DOI: $10.7868 / \mathrm{S} 0370274 \mathrm{X} 13100081$ 